\title{
Experimental evaluation of the torsional behaviour of thin walled beams: elastic and buckling situations
}

\author{
G. Belingardi, L. Peroni \& A. Scattina \\ Mechanics Department, Politecnico di Torino, Italy
}

\begin{abstract}
In the automotive engineering field, as well as in other structural applications, thin walled box beams are widely used. In car body construction this type of beam is fundamental, as it constitutes the base element of the frame structure.

The torsional stiffness is one of the main characteristics for a car body and is one of the main targets in the design of a new car. A good result in the body torsional stiffness can be achieved by an appropriate layout of the beams that constitute the frame, an appropriate design of the beam section, and an appropriate design of the joints that connect each other with the beams to build the frame.

The aim of the present paper is the analysis and comparison of the structural response of box-beams, typical elements of frame, submitted to torsion loads. Different cross-section shapes made by means of various types of joining technique are considered.

A torsion test machine has been designed and built, capable of testing different types of thin walled beam specimens. This test machine has different structural characterisation purposes: torsion stiffness, buckling and plastic post-buckling behaviour, static strength, and fatigue strength. The characteristics obtained by the adoption of a different joining technique can also be evaluated. The main constructive solutions adopted for the new test machine are reported in this work.

Experimental results obtained from a first series of tests carried out on simple thin walled box beams with two different cross sections, some of them obtained by using adhesive joints, are presented.
\end{abstract}

Keywords: torsion, torsional stiffness, thin walled boxed beams, buckling. 


\section{Introduction}

Thin walled metal structural components are very important in the design of the vehicles because of their very favourable strength and stiffness to weight ratio. These types of structures are very common in the design of the chassis and frame of different vehicles: cars, buses, trucks, trailers.

In the near future, in this type of construction, today's widely used materials, such as deep-drawing steels, will probably be substituted by new classes of materials such as high-strength steels (dual-phase, TRIP steels...), aluminium alloys, magnesium alloys and various types of polymeric materials and composites [1,2]. There are many reasons for this change: these new materials allow a more lightweight body to be obtained and at the same time safer vehicles characterized by higher strength and stiffness structure, and they permit the reduction of pollution emissions and operation costs.

Many problems have to be solved before the introduction of these new materials: some of their mechanical properties are still not completely known, the technologies usually adopted with traditional materials sometimes fail when simply translated in the new applications, and new environmental and worker protection problems can arise.

There are also additional problems related to joining systems. Often parts made of new materials cannot be assembled by traditional welding techniques, often alternative joint technologies offer interesting innovative solutions. Therefore car manufacturers are more than ever interested in the evaluation of the adhesive bonding technology that is the most promising joining solution, especially when dealing with the joining of different materials. Structural adhesive joints can be used with aluminium and composite parts in car body construction because they have a lot of advantages. Adhesives distribute the load over a larger area than mechanical joints and do not require holes, so result in a reduction of the stress concentration and an increase in the strength of the joint. Moreover the adhesive layer can perform as an insulating, protecting and damping material and it is possible to join different materials of almost any kind.

However, before adhesive bonding can be accepted on a wider scale, it is necessary to assess the performance characteristics of structures assembled by adhesive joints and to overcome doubts concerning their potential deficiencies. In particular it is important to investigate the behaviour of adhesive joints for fatigue life, on one hand, and under impact loads on the other.

The initial tests made in the past on adhesive joints evidenced some problems with this type of joining technology, for example a relatively low peel strength. However up to date structural adhesives have gained very high peel strength sufficient to guarantee very robust designs. Many other, supposed, drawbacks can be overcome by using state-of-the-art knowledge on adhesive joints construction. For example, nowadays modern structural adhesives can be applied directly on untreated surfaces, even if they are dirty and greasy, so surface preparation is not necessary. With regard to the long curing time required by adhesive polymerisation, if the bonded joint is made combined with other mechanical fastening methods or even with provisional fasteners [3], the 
problem can be effectively solved. The usual oven treatments in the car body paint cycle can be also used to get the adhesive polymerisation. There are still difficulties in designer and manufacturer attitudes, as also in recent years the world of adhesive joints has experienced large improvements.

In recent years, researchers have deeply investigated the behaviour of thin walled box beams under compressive and bending loads. We can find many published works with an extensive series of tests to characterize the plastic collapse of these types of structure [4-8].

In particular, in the automotive field, the properties of box beams are very important because they are widely used to make the body frame. In this area, one of the most important properties for a car body is the torsional stiffness. This value is one of the fundamental targets followed during the design of a new vehicle. For these reasons, the study of different section configurations for box beams and different types of joining technology used to build body parts loaded by torsion, are very interesting.

The aim of this work is to describe the new torsional test machine that has been designed and built at the Politecnico di Torino.

Some torsion tests have been carried out on thin walled box beams with different geometrical configurations and with different joining techniques. The obtained results allow the influence of these design features on beam structural performance to be investigated. In particular the paper reports the results obtained from tests on steel box beams made by two shells joined together with spot welding or adhesive bonding. The influence of geometric configuration and joining techniques on torsional stiffness and ultimate strength are evaluated.

\section{Test machine}

Experience and design solutions described in some previous published works [9-11] have been carefully considered. A specific test machine to make torsional tests on various thin walled box beams has been designed and built at the Reliability and Safety Laboratory of the II Faculty of Engineering of the Politecnico di Torino. In the design of this machine one of the main targets was its flexibility i.e. the possibility of performing different types of mechanical tests. The torsional stiffness and plastic collapse load of box beams can be evaluated as well as the strength of the different joining techniques used to make them. Fatigue tests on these types of structures can also be performed.

The test machine, shown in figure 1, is fastened to a cast iron table, which has $\mathrm{T}$ quarries to guarantee the fixture of its different components. The dimensions of the table have been designed to ensure a large enough stiffness value related to the maximum torque that will be applied during the tests. Substantially the test machine is simply composed of a hydraulic rotating motor that is aimed to supply the torque for the test. This motor can guarantee a maximum torque of $2400 \mathrm{Nm}$ at 210 bar oil pressure, with an angular stroke of $100^{\circ}$. This type of motor has been chosen for its high specific power compared with other types of actuators. The torsional actuator is mounted on a steel plate fixed on the cast iron table. On the rear part of the motor there is a LVDT angular position sensor that 
is fixed on the motor body and is connected to the motor shaft with a pin and an elastic coupling. It is intended to measure the angular position of the shaft. This type of sensor is also suitable for making fatigue tests without the contact problem. The stroke of the sensor is $\pm 80^{\circ}$ with a measurement precision of \pm $0.5 \%$.

On the front side of the motor, on the grooved out shaft, there is the fixture system for the specimen (see figure 1) made from a steel disk with four perpendicular $\mathrm{T}$ grooves. The fastening of the specimen is made with four steel rectangular blocks that can slide in the disc grooves and are fixed by bolts, nuts and a calibrated pin. The fixture system is mounted on the motor shaft by means of a grooved flange. This simple system is very similar to the chuck of a common lathe.

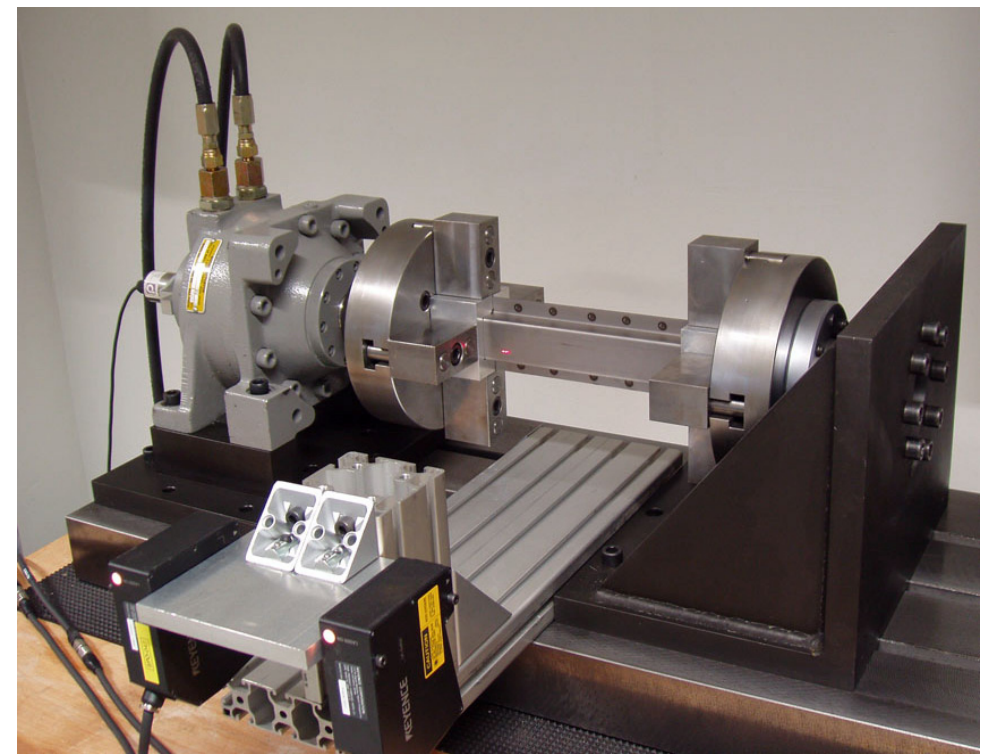

Figure 1: Torsional test machine.

On the other side of the cast iron table there is the second fixture system that is completely similar to the first one. This is bolted to a steel square designed to ensure a large enough stiffness, it can be mounted in different positions in order to allow different types of tests to be carried out. Between the fixture system and the square a torsional strain gage load cell is fixed with fastening screws. It can measure a maximum torque of $2000 \mathrm{Nm}$ with a precision of $0.1 \mathrm{Nm}$.

The hydraulic actuator is controlled by a hydraulic power unit designed for this application. The power of this hydraulic unit is $4 \mathrm{~kW}$ and the maximum pressure is 250 bar. The electric valves of the hydraulic unit are controlled by a personal computer with a National Instrument usb card and a dedicated Labview application software. This card is used also to acquire the signals of the twist angle and applied torque. 
The specimen to be tested is locked between the two fixture systems and, in order to ensure a perfect alignment, inside the specimen, on the two sides, a little pad fixed on the metal disc with a calibrated pin.

This test machine appears very simple and versatile. With this type of fixture system it is possible to lock specimens with different geometry and joining configurations. We can also test specimens with different lengths thanks to the steel square that can be properly positioned by sliding it along the cast iron table.

In particular, in order to perform the stiffness evaluation tests that are described in this work a particular equipment has been prepared. A little adjunctive frame with a vertical plate has been fixed on the cast iron table and two laser heads have been fastened on the plate. The laser sensors are intended to refine the measurement of the beam deformation, in particular for what concerns the elastic part of the torsional rotation. The laser beams measure the relative displacement of two points on one side of the specimen.

\section{Geometrical configuration and material properties}

The base component studied in this work is a simplified thin walled box beam typically used in the construction of a car body, it is made of a DC04 steel, a common deep-drawing low carbon steel. This material was chosen on the basis of several considerations: the still relatively widespread use in car body construction and easy market availability and low cost of this material.

In particular box beams with two different geometry configurations, obtained by joining two shells made by plastic bending deformation with different flanges, have been studied. The side width of the enclosed square section was $40 \mathrm{~mm}$ and the beam total length was $300 \mathrm{~mm}$ for all geometries of the examined cross section. The first box beam cross section is shown in figure 2. It is characterized by external flanges and, in this paper, will be named as the 'double hat' cross section according to the usual technical nomenclature. The external flanges, required by the spot welding joining technology, can also be used for adhesive bonding.
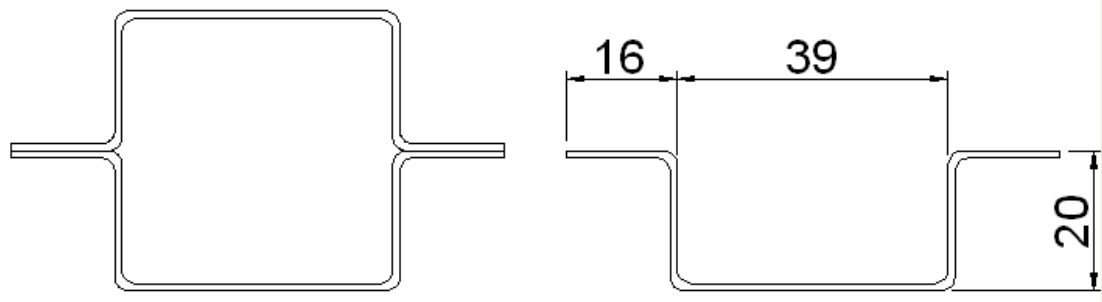

Figure 2: Double hat cross section.

The second box beam cross section, in this paper, will be named the 'double C' cross section, it is shown in figure 3. It is characterized by the absence of external flanges and probably cannot be obtained by using spot welding. It has 
been selected because its specific geometrical configuration takes full advantage of the mechanical properties of the adhesive material, as is confirmed by the results reported in Belingardi and Chiandussi [15].
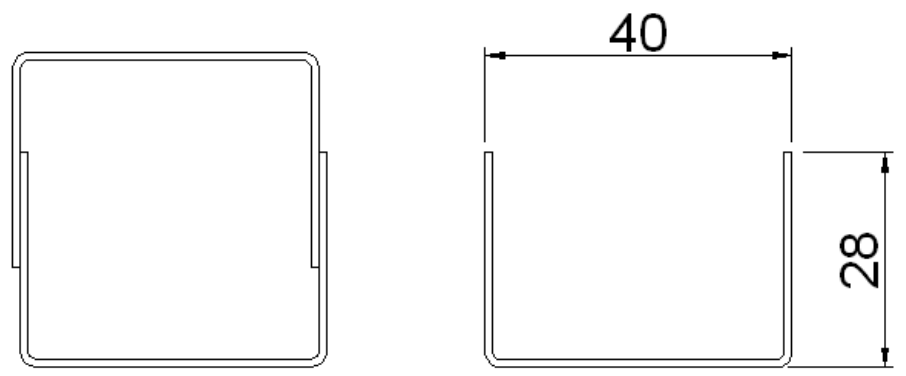

Figure 3: Double C cross section.

We have tested the first type of box beam joined by both spot welding and adhesive bonding while the second box beam is joined only by adhesive bonding.

The thickness of the metal sheet used to make the box beam is $1 \mathrm{~mm}$ and the corners in the cross section geometry are characterized by an internal radius of $1 \mathrm{~mm}$.

With regard to the box beam joined by spot welding, the spot diameter is $6 \mathrm{~mm}$ and the step between two spots is $40 \mathrm{~mm}$. The first spot is placed at $20 \mathrm{~mm}$ from the edge.

For adhesive bonding of the specimens, on the basis of previous experiences $[5,8,12,14]$, we have chosen an epoxy high performance structural adhesive Henkel $^{\circledR}$-Loctite ${ }^{\circledR}$ Hysol $^{\circledR}$ 9514. Shear strength can be up to $45 \mathrm{MPa}$ (depending on adherends), while peel strength can be up to $9 \mathrm{MPa}$. Operative temperature limit is quite high: the strength reduction becomes important only above $120^{\circ} \mathrm{C}$.

To obtain the specimens joined by adhesive bonding we have followed different steps. At first we have cleaned the two half shells with a specific chemical product. This first operation is aimed at removing dirt and grease from the surface. Next we operated a mechanical abrasion on the flanges where the adhesive will be put, so we have removed the oxide film on the surface of the adherends. After a second cleaning operation with a chemical product, we spread the adhesive only on one side of the adherends by means of a cartridge pistol. Then the adherends were positioned in contact with each other and fastened with some pincers. Finally the adhesive joint is cured for about 30 minutes at $170-180^{\circ} \mathrm{C}$ to get its polymerization.

\section{Results of experimental tests}

A series of experimental torsion tests was performed on the double $\mathrm{C}$ and double hat specimens. In particular, in order to develop the above described torsional test machine, some quasi-static tests were performed. 
During the torsion test, the torque was recorded together with the twist angle, thus the characteristic torque-angle curve is obtained. The quasi-static tests were interrupted after reaching the preset twist angle of $90^{\circ}$.

The curves obtained for different types of specimen are shown in figure 4, where the twist angle has been rated to the free length of the specimen.

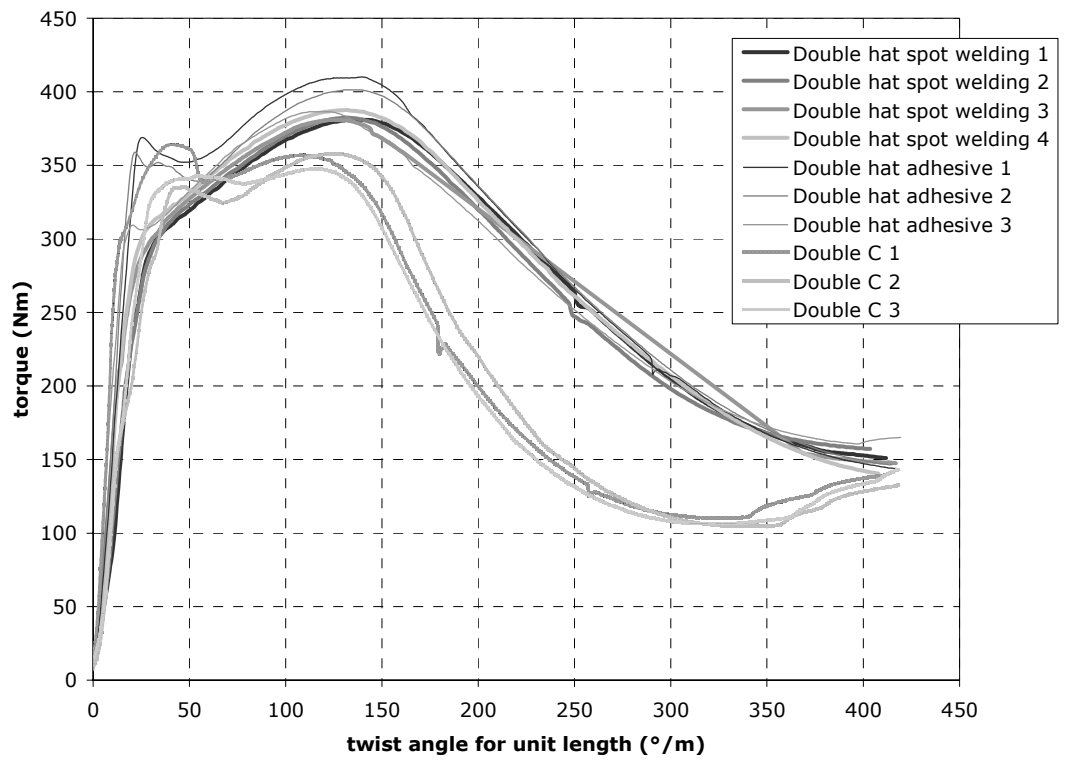

Figure 4: Torque-twist angle comparison for different types of specimen tested.

Starting from these curves, three structural properties of interest under torsional loading, namely the initial torsional stiffness $K$, the elastic limit torque $T_{e l}$ and the ultimate collapse torque $T_{u l t}$ are obtained and reported in table 1 . The values in the table are the average of the results of at least three test replications.

The stiffness values are calculated by a least square regression of data points on the first linear part of the curves. The elastic limit torque values are read on the curves at the point where there is an evident deviation of the curve from linearity. The ultimate torque is the maximum value reached by the torque. By going on with the beam twist after this point the section shape deformation becomes so large as to induce a progressive large decrease in the torque opposed to further torsional deformation.

During the plastic collapse, the beam corners remain unaffected by the deformation and the buckling takes place in the side walls where large folds, one for each flat side walls, come out (see figure 5). The wall is pushed inward and the material moves closer to the torsion axis. The fold is inclined with respect to the beam axis and does not have full beam length but it affects only a part of the beam length, suggesting a peculiar plastic collapse kinematic. 
Table 1: $\quad$ Obtained structural properties.

\begin{tabular}{|c|c|c|c|c|}
\cline { 3 - 5 } \multicolumn{2}{c|}{} & $\begin{array}{c}\text { Double hat } \\
\text { spot welding }\end{array}$ & $\begin{array}{c}\text { Double hat } \\
\text { adhesive } \\
\text { bonding }\end{array}$ & Double C \\
\hline Stiffness & $\left(\mathrm{Nm} /{ }^{\circ} / \mathrm{m}\right)$ & 17.44 & 19.92 & 19.59 \\
\hline $\begin{array}{c}\text { Elastic } \\
\text { limit }\end{array}$ & $(\mathrm{Nm})$ & 310 & 346 & 296.4 \\
\hline $\begin{array}{c}\text { Ultimate } \\
\text { torque }\end{array}$ & $(\mathrm{Nm})$ & 382.9 & 399.3 & 356.5 \\
\hline
\end{tabular}
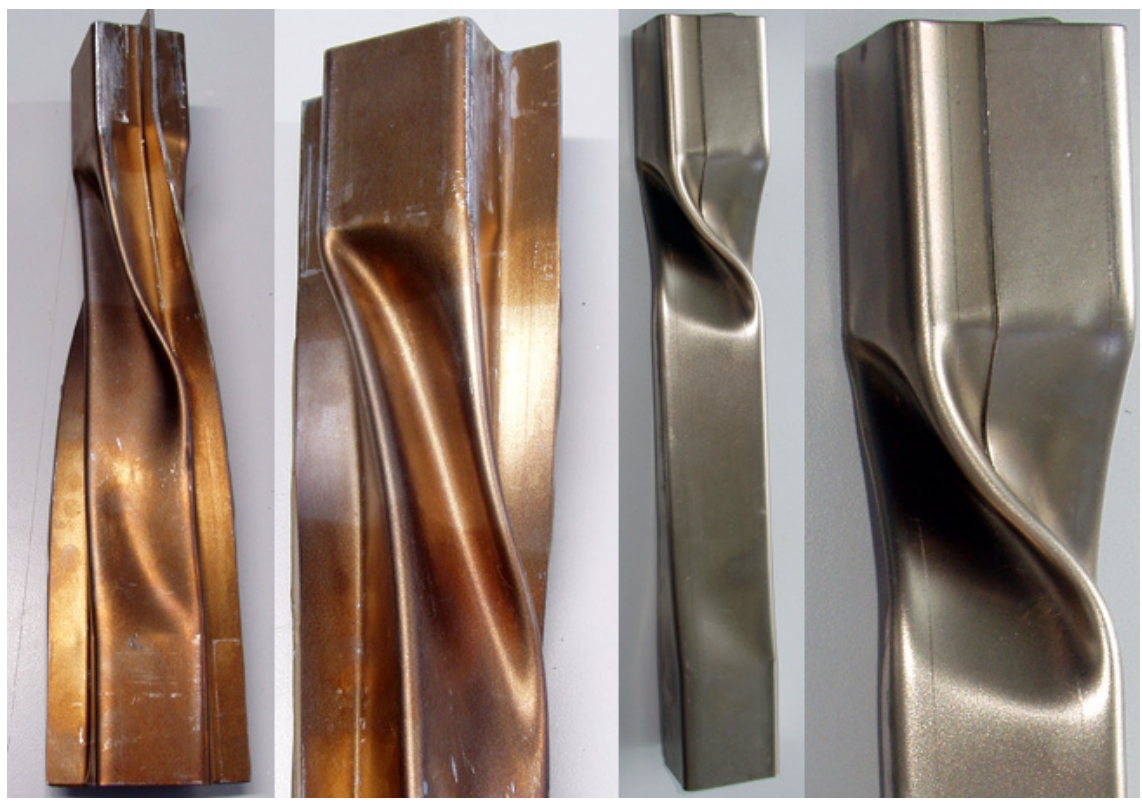

Figure 5: Deformed shape of the collapsed beam, typical shape for the two different considered sections.

The considered joints, both the adhesive and the spot weld, do not experience any failure or debonding at the end of such a big deformation. However in the specimen assembled by spot welding, during deformation, the flanges tend to detach from each other between two adjacent spots.

Generally we can see that the tests show a good reproducibility.

With regard to the double hat solution, the presence of the flanges at the middle of the two sides act as stiffeners to the walls that do not experience large folding deformation as the other two walls do. The use of adhesive bonding leads to a general better behavior in comparison with the specimen joined by spot welding. In fact, not only the values of the considered structural parameters are 
higher $(+14 \%$ in torsional stiffness, $+11 \%$ in elastic limit torque and $+5 \%$ in the ultimate torque) but also in general the entire curve is better.

With regard to the double $\mathrm{C}$ solution, the absence of the flanges makes it possible that all the four walls of the beam experience large folding deformation. The adhesive bonding has a very important effect on the torsional stiffness, as we can see in table 1 , for double $\mathrm{C}$ solution it is just a little less than for the double hat adhesive bonded solution. For the elastic limit, this type of cross section is the worst solution because it doesn't have the flanges which play an important role in strengthening during torsion but thanks to the adhesive, the value is not so far from the double hat joined by spot weld. In the plastic post-buckling deformation, the curves for these specimens are the lowest but we can note that after a certain twist angle, the torque value begins to increase: this is due to the fact that the folded specimen walls come in contact each other.

We have also observed the folding length in the post-buckling deformation is greater in the double hat specimen than in the double $\mathrm{C}$ specimen.

\section{Conclusion}

The behaviour of thin walled box beams subjected to torsional loading has been investigated in the quasi-static loading condition both in the elastic, buckling and plastic post-buckling phase of deformation.

A couple of different thin walled cross sections obtained by steel sheet simple bending and joined by both adhesive bonding and spot welding technologies were considered in order to compare their main structural performance.

The main objectives of the work were to develop a torsional test machine for thin walled box beams and to demonstrate the advantages of using adhesive bonding to improve torsional stiffness.

The results, reported in terms of torsional stiffness, of elastic limit and ultimate torque characteristic values, demonstrate an improvement when the adhesive joint technology is used. The advantage lies in the fact that adhesive gives a continuous connection of the sheets.

The specimen with a double hat cross section exhibits an increment of about $15 \%$ in torsional stiffness by the simple substitution of the usual spot welding technique with the adhesive bonding one.

The peculiar features of the kinematic of the post-buckling deformation that are characterized by the inward folding of the beam walls have been observed. The fold is inclined with respect to the beam axis and does not affect the whole side but only a limited length. The fold does not take place if, as in the double hat section, a flange is present because the flange acts as a wall stiffener and prevents its bending deformation.

\section{References}

[1] Davies, G. Materials for Automobile Bodies, Elsevier, Oxford, UK.

[2] Belingardi, G. \& Avalle M., Advanced materials for automotive applications. Mobility and Vehicle Mechanics, 30(2-3), pp. 51-65, 2004. 
[3] Avalle M. Experimental comparison of different innovative joining system for thin walled structures. Proc. of the ICEM12, $12^{\text {th }}$ Int. Conf. on Experimental Mechanics, paper No. 253, 2004.

[4] Fay, P.A. and G.D. Suthurst. 1990. "Redesign of adhesively bonded box beam sections for improved impact performance." Int. J. of Adhesion and Adhesives, No. 10(3): 128-138.

[5] Avalle, M., Belingardi G., Vadori R., Sul collasso assiale di travi in parete sottile realizzate con adesivi: primi risultati sperimentali. Proc. of the $X X X$ AIAS Nat. Conf., paper No. 016, 2001.

[6] Belingardi G., Goglio L., Rossetto M., Sul comportamento strutturale di travi scatolate con giunzioni incollate: risultati sperimentali di prove d'impatto. Proc. of the XXXI AIAS National Conference, paper No. 073, 2002

[7] Schneider F. \& Jones N. Impact of thin-walled high-strength steel structural sections. Proc. of the Inst. of Mech. Eng., No. 218 Part D pp. 131-158, 2004

[8] Belingardi G., Goglio L., Rossetto M., Impact behaviour of bonded built-up beams: experimental results. Int. J. of Adhesion and Adhesives, 25, pp. 173-180, 2002

[9] Chalioris, Torsional strengthening of rectangular and flanged beams using carbon fibre-reinforced-polymers - Experimental study. Construction and Building Materials, 22, pp. 21-29, 2008.

[10] Ridley-Ellis D.J., Owen J.S., Davies G., Torsional behaviour of rectangular hollow sections. J. of constructional steel research, 59, pp. 641-663, 2003

[11] Divo Bressan J., Kirchhof Unfer R., Construction and validation tests of a torsion test machine. J. of Materials Processing Tech., 179, pp. 23-29, 2006

[12] Baragetti S., Re P.A., Terranova A., Macchina per prove di presso-tenso torsione. Proc. of XXI AIAS Nat. Conf. 2002

[13] Peroni L., Avalle M., Belingardi G., Experimental investigation of the energy absorption capability of continuous joined crash boxes. Proc. of $20^{\text {th }}$ ESV Int. Conf. Paper number 07-0350, 2007

[14] Goglio L, Peroni L, Peroni M, Rossetto M., Caratterizzazione sperimentale in campo dinamico di un adesivo epossidico bicomponente. Proc. of the XXXIV AIAS Nat. Conf. Milano (Italy). Paper No. 129, 2005

[15] Belingardi G., Chiandussi G., Stress flow in thin walled box beams obtained by adhesive bonding joining technology. Int. J. of Adhesion and Adhesives, 24, pp. 423-439, 2004 